\title{
Coping and return to work: Measurement and theoretical issues
}

\author{
Magnus Odéen, Lars Ole Kristensen and Holger Ursin \\ Unifob Health, Bergen, Norway \\ Correspondence: Magnus Odeen, Unifob helse, Christies gate 13, 5015 Bergen \\ E-mail: Magnus.Odeen@unifob.uib.no Telephone: 55583906
}

\begin{abstract}
Sick leave and early departure from the workforce have serious adverse effects on both individuals and society. Motivation and coping are both important when attempting to return to work. In this article, we wanted to test if either of two coping instruments could predict return to work. Response outcome expectancies as defined in the Cognitive Activation Theory of Stress (CATS) (Ursin \& Eriksen, 2004) were measured by the CODE scale (Eriksen et al., 1997) and general self-efficacy was measured by the generalized self-efficacy scale (GSE) (Schwarzer \& Jerusalem, 1995). The instruments were tested in one group of rehabilitation patients $(\mathrm{N}=135)$ and one group of disability pensioners $(\mathrm{N}=85)$, who participated in return to work interventions in randomised controlled trials. None of the instruments could predict return to work at any point of measurement. Less than $10 \%$ of the theoretical range of the scales was used. The scales appear to measure a concept that is more stable than their underlying theory predicts, and they can not predict an important outcome. Results indicate that caution is advised when making inferences from these instruments to their underlying theories.
\end{abstract}

Norwegian sick leave statistics from the last thirty years reveal a pattern of a relatively constant level of long term sick leave (Statistics Norway, 2009). No discernable effect has been observed from continuing efforts by the government to combat the development, with increased demands to qualify for disability pensions and large national efforts to reduce sick leave (such as "Inkluderende Arbeidsliv", an inclusive work life agreement).

Sick leave is not only a problem for the society; sick leave also has negative effects for the individual. Multiple episodes of sick leave are in itself a risk factor for not returning to work (Côté et al., 2008). According to Norwegian sick leave statistics, a third of those who have been on continuous sick leave for 8 weeks never return to working life (Hauge \& Thune, 2008). More complex analyses (Lie et al., 2008) show that many long term sick listed individuals have erratic "careers" in the welfare system, where they frequently shift between work, sick leave, rehabilitation and vocational training. Disability pension is a risk factor for early death (Kivimaki et al., 2003).

\section{Motivation and coping}

It seems important to understand the reason why so many never return to working life. An explanation based purely on the patient's diagnosis seems unlikely. The largest groups of individuals on sick leave and disability suffer from musculoskeletal problems and/or mental health complaints, making up about half of the sick leave in Norway (NAV, 2009). One might assume that most of these individuals should have the prerequisites to function in working life most of their life.
Singling out those motivated to return to work is a key factor in identifying those more likely to return to work from disability pension (Magnussen et al., 2007). Desiring an outcome is not enough, you also have to believe that you can in fact produce the outcome (Bandura, 1997; Ursin \& Eriksen, 2004). As Lundberg pointed out (1999), having a positive response outcome expectancy is a necessity if the individual is to overcome short term obstacles to gain long term goals.

The CATS theory (Ursin \& Eriksen, 2004) proposes that learned response outcome expectancies govern the motivation of the individual to either actively attempt to change the situation, or remain passive or use mechanisms of defence. In a similar argument, Bandura (1997) proposed that self-efficacy for returning to work is a prerequisite for engaging in behaviour to actively change the situation. Self-efficacy theory proposes that efficacy beliefs (the individual's perception of his or her ability to produce a positive result from his or her effort) are what govern the individual's decision to attempt to return to working life.

According both to the self-efficacy and the CATS theory, coping expectations alter behavior in ways that affect results (Bandura, 1997; Ursin \& Eriksen, 2004). Individuals with high coping expectancies are more likely to act in ways that produce better outcomes than those who do not believe they can produce the desired effort and or outcome.

\section{Validity of the coping instruments}

Any useful theoretical concept needs an instrument that has both face validity and predictive validity for key outcomes. Only when we are confident that the 
operationalizations of the concepts are satisfactory, conclusions may be drawn as to the scientific value of the coping concepts themselves.

Returning to work would seem a good candidate for a test of the validity of such instruments for several reasons. Firstly, theory predicts that coping expectation should predict who will return to work or not. Secondly, participation in working life is an important factor in any individual's life. Being able or unable to return to work impacts the individual socially, financially and forms an important part of the individual's identity. Therefore it appears reasonable to suggest that overarching response outcome expectancies or general self-efficacy expectations should be more salient and important with this outcome than with outcome within more restricted domains.

In this article, we test the ability of two coping instruments, the Coping and Defence Inventory (CODE) (Eriksen et al., 1997) and the generalized self-efficacy scale (GSE) (Schwarzer \& Jerusalem, 1995) to predict return to work. We re-analysed two datasets where the CODE and GSE had been used to measure coping and where return to work was an outcome variable. The two groups were rehabilitation patients from Rauland rehabilitation centre and disability pensioners from Hordaland County. In both groups, we examined if either the GSE or the CODE could predict who would return to work. Furthermore, we discussed the validity of the inferences from instrument to theory.

\section{METHOD}

\section{Sample}

The first sample consisted of 135 rehabilitation clients who participated in a rehabilitation programme at the Rauland Rehabilitation Centre. This sample was obtained from a survey previously conducted by Øyeflaten (2005). The sample size originally counted 172 clients, but 37 of these were excluded because they did not complete the pre-test registration. The remaining 135 were analysed in this article. Out of these, $36 \%$ were male, with a mean age of 45 years $(\mathrm{SD}=8.4)$ ranging from 24 to 61 years.

The second sample was obtained from a randomized controlled trial previously conducted by Magnussen and colleagues (Magnussen et al., 2007). Originally, the sample consisted of 89 disability pensioners, $65 \%$ female, with a mean age of 49 years $(\mathrm{SD}=5.4)$. For the re-analysis, we used the 45 who were in the intervention group. Only 29 of the participants (64\%) did complete the intervention programme. 33 respondents answered the question about work status at 1 year, and were analysed in this article.

\section{Procedure}

The rehabilitation group

Rauland Rehabilitation Centre has specialized in helping rehabilitation clients who have been out of work for a long time. To enter the rehabilitation programme one needs to fulfil certain criteria. Participants need to have completed all necessary medical examinations. In addition the clients must have undergone other relevant medical treatments before being eligible. More than half the users had two or more medical diagnoses at intake. Participants were recruited by sending a questionnaire along with the intake letter two months prior to intake at Rauland (Øyeflaten, 2005). Register data were then obtained from official statistics at 3 months and 1 year after the rehabilitation programme.

The Rauland Rehabilitation Centre uses a multidisciplinary approach, and has a clear philosophy that focuses on the individual as an agent, responsible for its own rehabilitation. The programme aims at strengthening positive coping experiences and increase personal responsibility. For further details about the rehabilitation programme see Øyeflaten (2005).

\section{The disability group}

Recruitment was done by sending written invitations to selected low-back pain disability pensioners in Hordaland County, Norway. Those invited were 18-55 years, and had received full disability benefits for at least one year $(\mathrm{N}=431)$. Of those, about $20 \%(\mathrm{n}=89)$ agreed to participate in the study. Those who did not want to participate explained this by a lack of motivation, health complaints and/or choosing other treatment options (Magnussen et al., 2007).

The disability pensioners in this study were randomized into an intervention group $(\mathrm{n}=45)$ and a control group $(n=44)$. The intervention programme was composed of two three-hour sessions in small groups with information about low-back pain mechanisms that aimed to reduce fear-avoidance beliefs, and motivational interviewing aiming to disclose recourses and barriers perceived by the pensioners. In addition to the group sessions, one hour informative counselling about returning to work was provided. Also, each participant was offered the opportunity to receive a medical examination and an assessment of individual work ability status. Those motivated to attempt return to work were followed up by the local work office (NAV). For details concerning the intervention programme see Magnussen et al. (2007).

\section{Instruments}

\section{The CODE}

The Coping and Defence instrument (CODE) consists of 22 statements regarding how the respondent thinks he or she will react when facing a problem. Each statement is scored on a 4 point scale, ranging from very often (4), often (3), some times (2), to seldom or never (1). The CODE has 3 factors, "Depressive reaction pattern" and "Avoidance and defensive expectancy" and "Active problem solving". These are then combined by reversing the depressive and avoidance factor and adding the active problem solving into "Instrumental mastery oriented coping" (IMOC), which was 
used in this study. Since the CODE uses averages instead of sums, it has a theoretical range from 1 to 4 , where 1 is lowest and 4 highest. See Eriksen et al. (1997) for items and details about the questionnaire.

\section{The GSE}

The General Perceived Self-Efficacy Scale (GSE) was developed by Schwarzer and Jerusalem (1995) in order to measure generalized self-efficacy. The GSE originally consisted of 20 items, but was reduced to 10 items in 1981 (Schroder et al., 1998). The items are scored on a 4 point scale, giving a maximum score of 40 points (highest general self esteem) and a minimum of 10 points (lowest general self esteem). The instrument has only one factor.

\section{Return to work indicators}

In the rehabilitation group, register data about vocational status were used. The data were obtained from the national register of benefit registration (fd-trygd) three months and one year after the intervention. In order to facilitate interpretation and data analysis, outcomes were categorized into three categories: those entirely on sick leave (sick listed) (56\%), one group with different combinations of graded work status and intervention programmes (partly sick listed) (32\%), and finally a group consisting of those who got back to work full time (working full time) (11\%).

In the disability group, register data were also available, but were not used in this study. Return to work was more complex in this group, since it may be a long and time consuming process to obtain solutions adapted for disabled individuals. Instead, respondents were asked if they had succeeded in returning to work ("returned"), if they were in a process of returning to work ("in process"), or if they had not succeeded ("not returned").

Although this criterion is more subjective than using register data, we believe that asking the respondents this way is much better suited to capture meaningful differences between respondents. Pure register based return to work may be a too strict criterion for this group.

\section{Statistics}

Mean levels of the coping scores from the questionnaires were then compared between all 3 groups in both samples. Because of the number of tests being performed, we used a significance level of 0.001 to control for multiple testing. SPSS 15.0 statistical package was used for the statistical analysis.

\section{RESULTS}

Means and standard deviations are shown in tables 1 and 2. T-tests show that there were no significant differences in coping between those who returned to work and those who were still sick listed (see tables 3 and 4).

\section{Range of the scales}

The theoretical range of scores in the IMOC scale is 1 to 4 (the score is an average of scores from 1 to 4 ). For the GSE the theoretical range is 10-40. The observed range for IMOC was 2.58-2.85 in the disability group and 2.80-3.03 in the rehabilitation group. For the GSE the observed range was $27.22-29.00$ in the disability group and 28.13-30.81 in the rehabilitation group.

In other words, the observed range was only $7.6 \%$ of the theoretical range in the CODE and $8.9 \%$ in the GSE in the rehabilitation group. In the disability groups, the numbers were $9 \%$ and $5.9 \%$ respectively.

\section{DISCUSSION}

Neither the CODE nor the GSE could predict who would return to work in either group after controlling for multiple testing.

Other studies have found mixed results on predicting return to work with general self efficacy scales. One study showed that a different GSE scale (the ALCOS) could predict return to work in a Dutch study (Brouwer et al., 2009). A Danish study showed differences in GSE between sick listed and working Danes, but GSE could not predict return to work (Labriola et al., 2007). A Dutch study using a version of the Ut-

Table 1. Means and standard deviations for the rehabilitation group by return to work status for Instrumental Mastery Oriented Coping (IMOC) and General Self Efficacy (GSE).

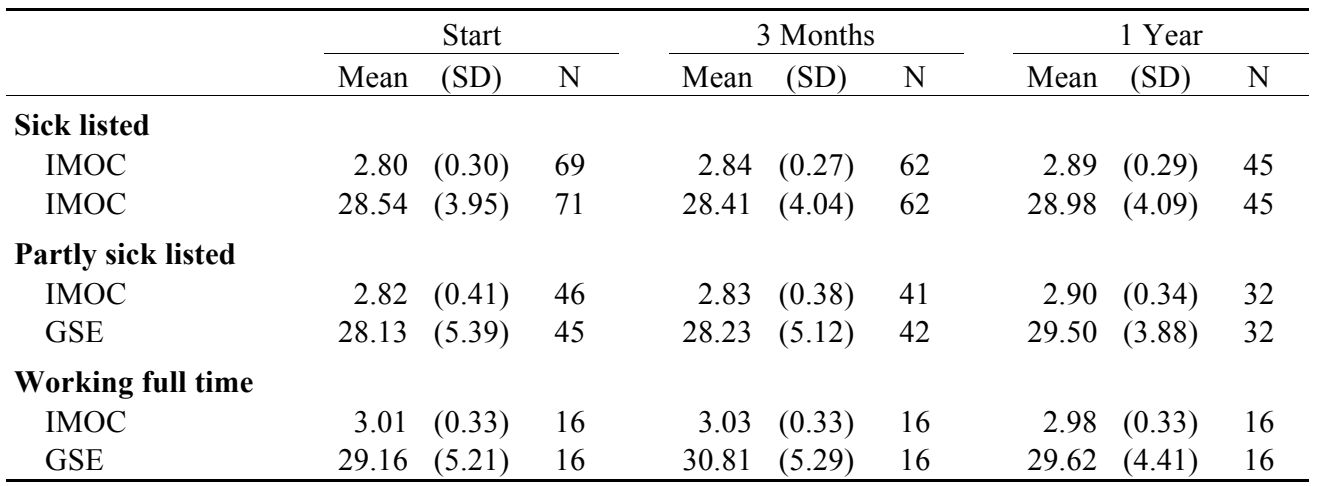


Table 2. Means and standard deviations of Instrumental Mastery Oriented Coping (IMOC) and General Self Efficacy (GSE) by return to work status in the disability group at 1 year follow up.

\begin{tabular}{crlr}
\hline & Mean & $(\mathrm{SD})$ & $\mathrm{N}$ \\
\hline Returned & & & \\
IMOC & 2.85 & $(0.23)$ & 9 \\
GSE & 29.00 & $(4.27)$ & 9 \\
In process & & & \\
IMOC & 2.73 & $(0.28)$ & 5 \\
GSE & 27.95 & $(2.94)$ & 5 \\
Not returned & & & \\
IMOC & 2.58 & $(0.36)$ & 19 \\
GSE & 27.22 & $(7.47)$ & 19 \\
\hline
\end{tabular}

recht Coping List (the CODE is a short version of the $\mathrm{UCL}$ ) found that those having an active coping style had a lower frequency and shorter duration and length of later sick leaves (van Rhenen et al., 2008).

The low number of attendees probably means that the study was not sufficiently powered to warrant a conclusion that coping could not predict return to work. That being said, the mean differences were very small, and all group means were within $10 \%$ of the range of the scales. Thus it would seem that the scale measured a very stable concept across outcomes and time. This is not consistent with the emphasis on learning and experience as modifiers of coping expressed in CATS and self-efficacy theory. Both CATS and self-efficacy theory propose that coping is not a static "trait" but a result of learning, which should have shown more variation across the groups and across time.

Furthermore, there are problems also with how the CODE and the GSE relate to their underlying theories. Bandura clearly states that self-efficacy is a domain specific concept, and that using "global" statements to assess self-efficacy is not correct (Bandura, 1997). Ajzen pointed out that this makes the concept much less useful, since researchers usually are interested in more general rather than specific behaviours (Ajzen, 1988). However, simply making a "general selfefficacy" scale seems to be a simplification of a larger underlying theoretical discussion, and thus the GSE falls somewhere in between a self-efficacy scale and a generalized response outcome expectancy scale.

The Utrecht coping list, and its short version (the CODE), was created as a way to reduce a comprehensive battery by using factor analysis and identifying items that formed a factor structure with three factors, active problem solving, depressive reaction pattern and emotion focused coping (Eriksen et al., 1997). However the questions and factors are about behaviour that individuals use when faced with difficulties, which then

Table 3. T-tests (significance levels) of between group differences in coping, measured with Instrumental Mastery Oriented Coping (IMOC) and General Self Efficacy (GSE) in the rehabilitation group. A significance level of 0.001 was used to control for multiple testing.

GSE, Rehabilitation group

\begin{tabular}{lccccccccc}
\hline & \multicolumn{3}{c}{ Baseline } & \multicolumn{4}{c}{ After 3 Months } & \multicolumn{3}{c}{ After 1 year } \\
& grp 1 & grp 2 & grp 3 & grp 1 & grp 2 & grp 3 & grp 1 & grp 2 & grp 3 \\
\hline grp 1 & 1.000 & & & & & & & & \\
grp 2 & 0.512 & 1.000 & & & & & & & \\
grp 3 & 0.600 & 0.635 & 1.000 & & & & & & \\
grp 1 & 0.380 & 0.092 & 0.056 & 1.000 & & & & & \\
grp 2 & 0.544 & 0.926 & 0.720 & 0.095 & 1.000 & & & & \\
grp 3 & 0.539 & 0.757 & 0.850 & 0.051 & 0.844 & 1.000 & & & \\
grp 1 & 0.787 & 0.325 & 0.338 & 0.496 & 0.343 & 0.298 & 1.000 & & \\
grp 2 & 0.800 & 0.224 & 0.258 & 0.334 & 0.249 & 0.214 & 0.920 & 1.000 & \\
grp 3 & 0.888 & 0.405 & 0.574 & 0.160 & 0.457 & 0.481 & 0.596 & 0.575 & 1.000 \\
\hline
\end{tabular}

IMOC, Rehabilitation Group

\begin{tabular}{lccccccccc}
\hline & \multicolumn{3}{c}{ Baseline } & \multicolumn{4}{c}{ After 3 months } & \multicolumn{3}{c}{ After 1 year } \\
& grp1 & grp2 & grp3 & grp1 & grp2 & grp3 & grp1 & grp2 & grp3 \\
\hline grp 1 & 1.000 & & & & & & & & \\
grp 2 & 0.102 & 1.000 & & & & & & & \\
grp 3 & 0.017 & 0.759 & 1.000 & & & & & & \\
grp 1 & 0.855 & 0.069 & 0.008 & 1.000 & & & & & \\
grp 2 & 0.109 & 0.890 & 0.625 & 0.073 & 1.000 & & & & \\
grp 3 & 0.032 & 0.810 & 0.473 & 0.016 & 0.951 & 1.000 & & & \\
grp 1 & 0.780 & 0.175 & 0.042 & 0.643 & 0.190 & 0.081 & 1.000 & & \\
grp 2 & 0.285 & 0.388 & 0.154 & 0.203 & 0.454 & 0.347 & 0.448 & 1.000 & \\
grp 3 & 0.175 & 0.357 & 0.119 & 0.110 & 0.433 & 0.330 & 0.323 & 0.915 & 1.000 \\
\hline
\end{tabular}

Group 1: On sick leave

Group 2: Partly sick listed

Group 3: Working full time 
Table 4. T-tests of Instrumental Mastery Oriented Coping (IMOC) and General Self Efficacy (GSE) in the disability group. A significance level of 0.001 was used to control for multiple testing.

GSE, Disability Group

\begin{tabular}{lccc}
\hline & \multicolumn{3}{c}{ After 1 year } \\
\cline { 2 - 4 } & grp 1 & grp 2 & grp 3 \\
\hline grp 1 & 1.000 & & \\
grp 2 & 0.330 & 1.000 & \\
grp 3 & 0.517 & 0.903 & 1.000 \\
\hline
\end{tabular}

IMOC, Disability Group

\begin{tabular}{lccc}
\hline & \multicolumn{3}{c}{ After 1 year } \\
\cline { 2 - 4 } & grp 1 & grp 2 & grp 3 \\
\hline grp 1 & 1.000 & & \\
grp 2 & 0.385 & 1.000 & \\
grp 3 & 0.049 & 0.405 & 1.000 \\
\hline
\end{tabular}

Group 1: Returned

Group 2: In process

Group 3: Not returned

is presumed to be based on underlying response outcome expectancy. The underlying expectancy and the behaviour following it may be very closely related, but they are not the same thing. Thus there is still a theoretical problem that the instrument does not measure expectations more directly.

An alternative explanation would be to say that coping does not matter for return to work. It would perhaps seem a more parsimonious explanation; especially since both the CODE and the GSE has had extensive validation. This is an explanation that cannot be ruled out. However, it would seem contra-intuitive and would mean that our understanding of coping, our understanding of return to work, or both, would have to be changed. Doing so without a large degree of confidence in our measurement of coping would seem premature and ill-considered.

There are theoretical and methodological issues with the instruments. Until we have instruments that more clearly demonstrate expected correlations with important outcome variables, there is reason to advice some caution against drawing too strong conclusions about the relationship between coping and return to work. This is especially true when using the CODE and GSE and inferring to the theoretical framework of the CATS theory or General Perceived self-efficacy.

\section{Limitations}

The disability pensioners represented a very small and in all probability very skewed selection of the invited group of disability pensioners. Although we cannot know for sure, it seems reasonable to assume that motivation for returning to work was higher in the studied group than the general disability population, and that this probably affected the overall scores on the coping questionnaires. Likewise, the rehabilitation groups were selected based on their motivation to return to work. Thus the study in no way claims that the levels of coping represented in the disability and rehabilitation group are representative for the general population of either disability pensioners or rehabilitation candidates in Norway.

A more serious problem might be that there may be a selection bias, where only the patients and pensioners with the highest coping participates in interventions and fills out questionnaires, thus reducing the variability in the groups through restriction of range. Thus if the group represented only the most coping individuals in the groups, the lack of variation in the forms could be caused by the fact that only a small selection of coping individuals took part in the interventions. Such an explanation cannot be ruled out even though it is not consistent with the low number of individuals returning to work in both groups.

\section{CONCLUSION}

Given the disappointing results of the two instruments, and the theoretical problems with the instruments, we feel that a moderate degree of caution is warranted when inferring from results from these instruments to CATS or self-efficacy theory, and that more research on measurement of coping is needed, including further validation and possible testing of new coping instruments.

\section{REFERENCES}

Ajzen I (1988). Attitudes, personality, and behavior. Buckingham: Open University Press.

Bandura A (1997). Self-efficacy the exercise of control. New York: Freeman.

Brouwer S, Krol B, Reneman MF, Bültmann U, Franche R, van der Klink JJL, et al. (2009). Behavioral determinants as predictors of return to work after long-term sickness absence: an application of the theory of planned behavior. J Occup Rehab, 19 (2), 166-174.

Côté P, Baldwin M, Johnson W, Frank J, Butler R (2008). Patterns of sick-leave and health outcomes in injured workers with back pain. Eur Spine J, 17 (4), 484-493.

Eriksen HR, Olff M, Ursin H (1997). The CODE: A revised battery for coping and defense and its relations to subjective health. Scand J Psychol, 38 (3), 175-182.

Hauge L, Thune O (2008). Kor stor del av dei langtidssjukmeldte fell ut av arbeidsmarknaden? Oslo: NAV. 
Kivimaki M, Head J, Ferrie JE, Shipley M, Vahtera J, Marmot M (2003). Sickness absence as a global measure of health: evidence from mortality in the Whitehall II prospective cohort study. BMJ, 327 (7411), 364.

Labriola M, Lund T, Christensen KB, Albertsen K, Bültmann U, Jensen JN, et al (2007). Does self-efficacy predict return-to-work after sickness absence? A prospective study among 930 employees with sickness absence for three weeks or more. Work, 29(3), 233-238.

Lie SA, Eriksen HR, Ursin H, Hagen E (2008). A multi-state model for sick-leave data applied to a randomized control trial study of low back pain. Scand J Public Health, 36 (3), 279-283.

Lundberg U (1999). Stress responses in low-status jobs and their relationship to health risks: Musculoskeletal disorders. Ann NY Acad Sci, 896, 162-172.

Magnussen L, Strand LI, Skouen JS, Eriksen HR (2007). Motivating disability pensioners with back pain to return to work - a randomized controlled trial. J Rehab Med, 39 (1), 81-97.

NAV (2009). Sykefraværstilfeller 3 kv 2001-2008. Diagnose og kjønn. Antall. Retrieved 29/06, 2009, from http://www.nav.no/155111.cms.

van Rhenen W, Schaufeli W, van Dijk F, Blonk R (2008). Coping and sickness absence. Int Arch Occup Environ Health, 81 (4), 461-472.

Schroder KEE, Schwarzer R, Konertz W (1998). Coping as a mediator in recovery from cardiac surgery. Psychol Health, 13 (1), 83-97.

Schwarzer R, Jerusalem M (1995). The Generalized Self-Efficacy Scale. In: Weinman J, Wright S, Johnston M (Eds), Measures in health psychology: A user's portfolio. Causal and control beliefs. Windsor, UK: NFERNelson, 35-37.

Statistics Norway (2009). Sickness absence, self- and doctor-certified. Retrieved October 15, 2009, from http://www.ssb.no/english/subjects/06/02/sykefratot_en/.

Ursin H, Eriksen HR (2004). The cognitive activation theory of stress. Psychoneuroendocrinology, 29, 567-592.

Øyeflaten I (2005). kjennetegn ved langtidspsykemeldte personer som kommer tilbake i yrkesaktivitet etter arbeidsrettet rehabilitering. Universitetet i Oslo, Seksjon for Helsefag, Det medisinske fakultet. 